\title{
Emended Description of Capnocytophaga gingivalis
}

\author{
JACK LONDON, ${ }^{1 *}$ ROGER A. CELESK, ${ }^{1 \dagger}$ ANGELIKA KAGERMEIER, ${ }^{1}$ AND JOHN L. JOHNSON ${ }^{2}$ \\ Microbiology Section, Laboratory of Microbiology and Immunology, National Institute of Dental Research, Bethesda, \\ Maryland 20205, ${ }^{1}$ and Department of Anaerobic Microbiology, Virginia Polytechnic Institute and State University,
} Blacksburg, Virginia $24061^{2}$

\begin{abstract}
Comparisons of deoxyribonucleic acid base sequence homology and phenotypic properties of Capnocytophaga gingivalis and Cytophaga sp. DR2001 and DR2002 revealed that the three strains belonged to the same species but that the original species description was not accurate. An emended description of $C$. gingivalis is presented.
\end{abstract}

The genus Capnocytophaga was created for a group of oral gliding bacteria that can be distinguished from members of the genus Cytophaga by several physiological criteria (6, 8). Salient among these are (i) a requirement for $10 \% \mathrm{CO}_{2}$ in the gas phase of a culture, (ii) a strictly fermentative physiology, (iii) the inability to liquify agar, and (iv) an absence of catalase activity. While these oral microorganisms were being described, other investigators were isolating and characterizing similar microbes from the same general econiche (namely, human periodontal pockets) $(2,3)$. However, the latter isolates were tentatively assigned to the genus Cytophaga because, like their soil and aquatic counterparts, they required no added $\mathrm{CO}_{2}$ in the gas phase for growth and were not restricted to a strictly fermentative existence (8). Before two " $\mathrm{CO}_{2}$-nonrequiring" oral gliding bacteria (strains DR2001 and DR2002) were described for the purpose of assigning specific epithets, deoxyribonucleic acid hybridization studies with these two isolates and the three type strains of Capnocytophaga species were performed. Strains DR2001 and DR2002 shared between 76 and $84 \%$ of their base sequences; labeled deoxyribonucleic acids of strains DR2001 and DR2002 also showed 82 and 69\% homology, respectively, with deoxyribonucleic acid from Capnocytophaga gingivalis ATCC $33624^{\mathrm{T}}\left(=\right.$ strain $\left.27^{\mathrm{T}}[6]\right)(\mathrm{T}=$ type strain). Since the three strains shared more than $65 \%$ of their base sequences, it was clear that they belonged to the same species (4) and that a new specific epithet could not be assigned to strains DR2001 and DR2002. Phenotypic comparisons of strains DR2001, DR2002, and ATCC $33624^{\mathrm{T}}$ were undertaken to resolve the conflicting observations surrounding the $\mathrm{CO}_{2}$ requirement and obligatory fermentative metabolism of these organisms.

A comparative study of the physiological traits of the three strains yielded the results described below.

Capnocytophaga gingivalis ATCC $33624^{\mathrm{T}}$ did not require an atmosphere enriched with $\mathrm{CO}_{2}$ to grow either aerobically, anaerobically, or in static culture (Table 1). Furthermore, supplementing the atmosphere with $10 \% \mathrm{CO}_{2}$ or adding a source of $\mathrm{CO}_{3}^{-2}$ to the medium did not increase the growth rate or final cell yield above that observed in the control cultures.

The three strains readily adapted to aerobic growth, with concomitant oxidative dissimilation of glucose. Aerobic dissimilation of glucose by Cytophaga sp. strains DR2001 and DR2002 was manifested by (i) a doubling of the cell mass per mole of hexose utilized compared with anaerobic glucose

\footnotetext{
* Corresponding author.

† Present address: Miles Laboratories, West Haven, CT 06516.
}

utilization and (ii) an absence of acid production at the cessation of growth (7). The succinic acid normally produced from the fermentation of glucose by Cytophaga sp. strains DR2001 and DR2002 was not found in aerobic cultures grown at the expense of glucose because the organisms induced a functional tricarboxylic acid cycle capable of completely dissimilating glucose (7). Although the end products of aerobic glucose metabolism by Capnocytophaga gingivalis were not specifically identified, the cell yields of aerobic cultures also doubled, and the $\mathrm{pH}$ remained neutral, indicating that most of the glucose was respired to $\mathrm{CO}_{2}$ and water.

Phenotypically, strains DR2001 and DR2002 were in-

TABLE 1. Characteristics of Capnocytophaga gingivalis ATCC $33624^{\mathrm{T}}$ and Cytophaga species strains DR2001 and DR2002

\begin{tabular}{|c|c|c|c|}
\hline Characteristic & $\begin{array}{l}\text { Capnocy- } \\
\text { tophaga } \\
\text { gingivalis }\end{array}$ & $\begin{array}{l}\text { Strain } \\
\text { DR2001 }\end{array}$ & $\begin{array}{c}\text { Strain } \\
\text { DR2002 }\end{array}$ \\
\hline Growth in standing culture ${ }^{a}$ & + & + & + \\
\hline Growth in air (shaken) ${ }^{a}$ & $+(20)^{b}$ & $+(24)$ & $+(35)$ \\
\hline Anaerobic growth ${ }^{c}$ & $+(10.8)$ & $+(12.2)$ & $+(14)$ \\
\hline Respiratory growth ${ }^{d}$ & + & + & + \\
\hline Catalase & - & - & - \\
\hline $\begin{array}{l}\text { Guanine-plus-cytosine content } \\
\text { (mol \%) }\end{array}$ & $34-41^{e}$ & 40 & 40 \\
\hline \multicolumn{4}{|l|}{$\begin{array}{l}\text { Growth or acid production or } \\
\text { both from: }\end{array}$} \\
\hline Glucose & $++^{e}$ & + & + \\
\hline Sucrose & + & + & + \\
\hline Maltose & + & + & + \\
\hline Mannose & + & + & + \\
\hline Starch & - & - & - \\
\hline Dextran & + & - & - \\
\hline Glycogen & - & - & - \\
\hline \multicolumn{4}{|l|}{ Acid end products } \\
\hline Succinate & $+e$ & + & + \\
\hline Acetate & + & + & + \\
\hline \multicolumn{4}{|l|}{ Growth in and hydrolysis of: } \\
\hline Agar & $-{ }^{e}$ & - & - \\
\hline Chitin & - & - & - \\
\hline Cellulose & - & - & - \\
\hline Flexirubinf & + & + & + \\
\hline
\end{tabular}

${ }^{a}$ Growth in the absence of added carbonate.

$b$ Values in parentheses are milligrams of cells (dry weight) per mole of glucose.

C As determined by using the GasPK system (atmosphere containing $95 \%$ $\mathrm{H}_{2}$ and $5 \% \mathrm{CO}_{2}$ )

${ }^{d}$ Aerobic growth at the expense of glucose with no change in $\mathrm{pH}$

e Data from reference 8 .

${ }^{f}$ Extracted and identified by the method of Achenbach and Kohl (1). 
distinguishable from Capnocytophaga gingivalis ATCC $33624^{\mathrm{T}}$ (Table 1).

Therefore, we suggest that the description of Capnocytophaga gingivalis be emended to reflect the physiological characteristics described above. Although the genus epithet no longer reflects one of the salient properties of the organism, the fact that the name and description of the organism appear in a valid publication mandates its continued use. As presently described, Capnocytophaga gingivalis differs from fermentative forms of nonoral gliding bacteria like Cytophaga fermentans and Flexibacter succinicans only with respect to econiche, optimal growth temperature, presence or absence of catalase, and, in one instance (Cytophaga fermentans), the ability to hydrolyze, but not utilize, agar (5).

Emended description of Capnocytophaga gingivalis. Single flexible rods 0.3 to 0.5 by 3 to $8 \mu \mathrm{m}$. The guanine-pluscytosine content of the deoxyribonucleic acid ranges from 35 to $41 \mathrm{~mol} \%$.

Metabolism is fermentative, with glucose fermented to succinic and acetic acids, or respiratory, with glucose metabolized to $\mathrm{CO}_{2}$ and water by using oxygen as the terminal electron acceptor. Yeast extract, peptones, and other nitrogenous compounds support aerobic growth. Starch, dextran, agar, chitin, and cellulose are not hydrolyzed. Glucose, sucrose, mannose, and maltose are fermented; galactose, cellobiose, trehalose, L-arabinose, D-xylose, D-ribose, Lrhamnose, esculin, melezitose, raffinose, D-mannitol, and D-glucitol are not fermented.

Substrate amounts of carbon dioxide are not required for fermentation or oxidation of glucose but may be required for initial isolation.

Orange pigment is often produced when the organism is grown either aerobically or anaerobically. Capnocytophaga gingivalis is facultatively aerobic. The optimum growth temperature is ca. $37^{\circ} \mathrm{C}$; growth also occurs at $30^{\circ} \mathrm{C}$.

\section{LITERATURE CITED}

1. Achenbach, H., and W. Kohl. 1978. Investigations of the pigments from Cytophaga johnsonae Cyjl. Arch. Microbiol. 117:253-257.

2. Celesk, R. A., and J. London. 1980. Attachment of oral Cytophaga species to hydroxyapatite-containing surfaces. Infect. Immun. 29:768-777.

3. Celesk, R. A., R. M. McCabe, and J. London. 1979. Colonization of the cementum surface of teeth by oral gram-negative bacteria. Infect. Immun. 26:15-18.

4. Johnson, J. 1973. Use of nucleic acid homologies in the taxonomy of anaerobic bacteria. Int. J. Syst. Bacteriol. 23:308-315.

5. Leadbetter, E. R. 1974. Order II. Cytophagales nomen novom, p. 99-107. In R. E. Buchanan and N. E. Gibbons (ed.), Bergey's manual of determinative bacteriology, 8th ed. The Williams \& Wilkins Co., Baltimore.

6. Leadbetter, E. R., S. C. Holt, and S. S. Socransky. 1979 Capnocytophaga: a new genus of gram negative gliding bacteria. I. General characteristics, taxonomic considerations and significance. Arch. Microbiol. 122:9-16.

7. London, J., R. Celesk, and P. Kolenbrander. 1982. Physiological and ecological properties of the oral gram negative gliding bacteria capable of attaching to hydroxyapatite, p. 76-85. In R. J. Genco and S. E. Mergenhagen (ed.), Host-parasite interactions in periodontal diseases. American Society for Microbiology, Washington, D.C.

8. Socransky, S. S., S. C. Holt, E. R. Leadbetter, A. C. R. Tanner, E. Savitt, and B. F. Hammond. 1979. Capnocytophaga: a new genus of gram negative gliding bacteria. III. Physiological characterization. Arch. Microbiol. 122:29-33. 